Polymer Journal, Vol. 39, No. 9, pp. 923-927 (2007)

(C) 2007 The Society of Polymer Science, Japan

\title{
Synthesis and Thermotropic Liquid Crystalline Behavior of Copolymers Containing Ether Ketone and Ester Links
}

\author{
Yanhua YANG, Xiaoye MA, Limei ZHANG, Lifeng WANG, and Zhenhua JIANG ${ }^{\dagger}$ \\ College of Chemistry, Jilin University, Jiefang Road 2519, Changchun, 130023 China
}

(Received December 20, 2006; Accepted April 24, 2007; Published July 18, 2007)

\begin{abstract}
Copolymers containing ether ketone and ester links were synthesized by high temperature solution condensation and were characterized by Fourier transform infrared (FT/IR) spectroscopy, differential scanning calorimetry (DSC), wide angle X-ray diffraction (WAXD) and polarized light microscopy (PLM). The melting behavior and liquid crystalline transition temperatures of the homopolymers and copolymers were dependent on the composition of trimer content. The transition temperatures could be observed to decrease at first and increase subsequently; i.e. surpass a minimum, with the increment of trimer content. Thermotropic liquid crystalline behaviors were observed in the copolymers containing 20,40,50 and $60 \mathrm{~mol} \%$ trimer. But the further addition of the trimer content resulted in the gradual loss of liquid crystallinity. The crystalline to liquid crystalline transition $\left(\mathrm{T}_{\mathrm{m}}\right)$ and liquid crystalline to isotropic transition $\left(\mathrm{T}_{\mathrm{i}}\right)$ appeared in the DSC curves, whereas the trimer-based homopolymer had only a melting transition. The polymers were thermally stable up to $400^{\circ} \mathrm{C}$. WAXD results indicated that the copolymers showed a continuous change of the diffraction peaks from sharp main crystalline reflections for crystalline Homo-C to strong broad dispersed peak for liquid crystalline TLCP. [doi:10.1295/polymj.PJ2006196]

KEY WORDS Liquid Crystalline Polymers (LCP) / Ether Ketone Links / Compatibilizer /
\end{abstract}

Poly (ether ether ketone) (PEEK) is a semicrystalline aromatic thermoplastic with remarkable properties at high temperature. It offers an excellent balance of properties: toughness, strength, and rigidity, good electrical properties, as well as chemical and radiation resistance. Thus PEEK becomes candidates in applications such as electrical connectors, molded parts and high strength composites. ${ }^{1,2}$ However, the high melting temperatures and high melt viscosities of PEEK are the shortcomings associated with processing these materials. ${ }^{3}$ The unique physical and chemical properties of thermotropic liquid crystalline polymers (TLCP), such as polyesters and polyamides, allow them to form liquid crystalline structures at manageable temperatures and be melt-processed in this state to form high-strength fibers or self-reinforced molded plastics. ${ }^{4}$ Blends of TLCP with highperformance thermoplastics including PEEK known as in-situ composites ${ }^{5}$ have attracted a great deal of interest because they can solve some problems that arise during the processing of conventional fiber-reinforced composites, such as increase in melt viscosity, thermal degradation, poor dispersion of fibers, processing machinery wear-out, and breakage of solid fibers. ${ }^{6,7}$ In practice, however, the properties of TLCP/polymer blends fall far short of expectations, largely as a result of poor interfacial adhesion because most of the thermoplastics studied so far are either incompatible or only partially compatible with TLCP. The mechanical properties would be improved if the blends were mis- cible or compatible. Thus, recent work in the field has been directed at developing compatibilizers to lower the interfacial tension and improve the interfacial adhesion. ${ }^{8,9}$

Compatibilizing agents are generally block or graft copolymers possessing segments with chemical structures or solubility parameters that are similar to those of the polymers being blended. Acting as polymeric surfactants, these copolymers reduce the interfacial tension, thus promoting interfacial adhesion, a finer dispersion and more uniform distribution of the dispersed phase.

Previous studies on syntheses of compatibilizer for TLCP/PEEK blends are very few. ${ }^{10,11} \mathrm{~A}$ series of homopolymers and copolymers based on trimer containing ether-ketone links and monomers for TLCP were designed and synthesized. The effect of compositions of copolymers on their thermal properties and liquid crystallinity (or crystallinity) was studied in detail in order to choose an appropriate compatibilizer suited to the melt-processing conditions of blends.

\section{EXPERIMENTAL}

\section{Materials}

Terephthaloyl dichloride (TPC) (CP) purchased from Shanghai Tingxin Chemical Factory was recrystallized from n-hexane which was previously distilled from $\mathrm{CaH}_{2}$. Benzophenone (CP) obtained from Beijing Chemical Factory was used as received.

${ }^{\dagger}$ To whom correspondence should be addressed (Tel: 86-0431-85168886, Fax: 86-0431-88925459, E-mail: yhyang@jlu.edu.cn). 


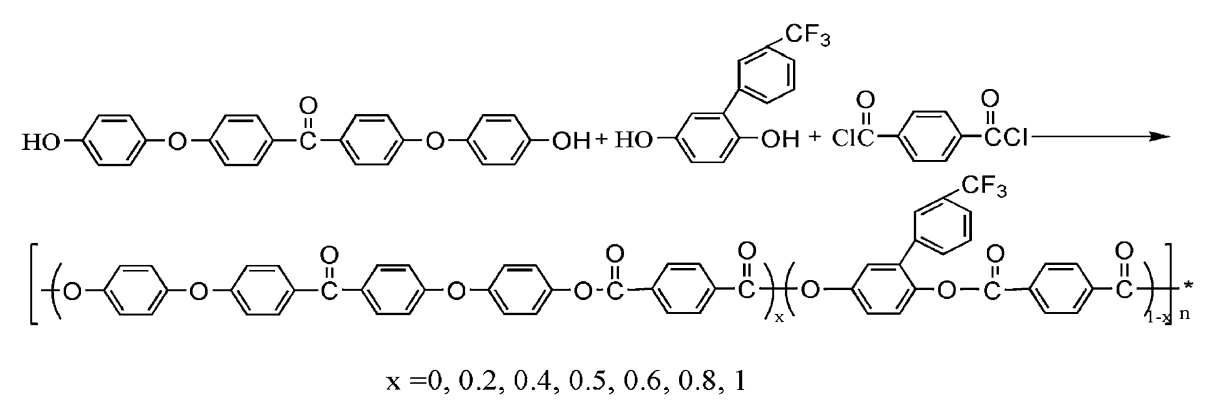

Scheme 1. Synthesis route of copolymers.

2-(3'-Trifluoromethylphenyl) hydroquinone (TFHQ) $\left(\mathrm{mp}=108^{\circ} \mathrm{C}\right)$ and trimer were prepared according to the procedure reported by literatures respectively. ${ }^{12,13}$ Other reagents and solvents were purified by common methods before use.

\section{Measurements}

A Mettler Toledo Differential Scanning Calorimeter $\left(\mathrm{DSC} 821^{\mathrm{e}}\right)$ was used to measure thermal transition temperatures for the polymers at rate of $20^{\circ} \mathrm{C} / \mathrm{min}$ under nitrogen atmosphere, and the maximum endotherm was taken as the transition temperature. Indium and zinc was used as the reference for the calibration of temperature and heat flow. The thermogravimetric analysis was performed on Perkin-Elmer Pryis 1 TGA Analyzer under a constant air purge at rate of $20^{\circ} \mathrm{C} / \mathrm{min}$. The inherent viscosities $\left(\eta_{\text {iv }}\right)$ of the polymers were measured in $50 / 50(\mathrm{w} / \mathrm{w})$ p-chlorophenol/tetrachloroethane solution at $\mathrm{T}=25 \pm 0.1^{\circ} \mathrm{C}$ $(c=0.1 \mathrm{~g} / \mathrm{dL})$ with Ubbelodhe viscometer. Liquid crystalline texture was examined via Leica DMLP polarizing light microscopic (PLM) equipped with a Linkam TMS600 hotstage. The photographs were taken at temperature above the samples' $\mathrm{T}_{\mathrm{m}}$. The sample were prepared by placing a small amount of the polymer (powder form) on thin circular cover glass and another one was placed on top of the powder. A thin film was obtained by applying a slight pressure on the top cover glass at temperatures above its $\mathrm{T}_{\mathrm{m}}$ using a hot plate. WAXD investigations were carried out at room temperature with samples' powder, by SHIMADAZU XR-6000 type diffractometer, using $\mathrm{Ni}$ filtered $\mathrm{Cu} \mathrm{K}_{\alpha}$ radiation. The diffraction scans were collected between $2 \theta$ values of 5 and $50^{\circ}$ using steps of $4^{\circ}$.

\section{Synthesis of homopolymer and copolymer}

Appropriate molar ratios of TFHQ, TPC and trimer were added to a solution of benzophenone in $100 \mathrm{~mL}$ flask fitted with mechanical stirrer, thermometer, gas inlet and dried tube under nitrogen atmosphere. The mixture was heated to $180^{\circ} \mathrm{C}$ for $2 \mathrm{~h}, 200^{\circ} \mathrm{C}$ for $36 \mathrm{~h}$ and $250^{\circ} \mathrm{C}$ for $8 \mathrm{~h}$ with a constant flow of nitrogen to remove $\mathrm{HCl}$ completely. The gel-like reaction mixture was diluted with benzophenone and precipitated into methanol, filtered and extracted in a Soxhlet with methanol. The brown-yellow or pale solid obtained was dried under vacuum at $120^{\circ} \mathrm{C}$ for $24 \mathrm{Hr}$. Homopolymers were prepared by the reactions of equivalent molar ratios of TPC with TFHQ or trimer using the same procedure mentioned above.

The synthesis route of copolymers in this study was outlined in Scheme 1.

\section{RESULTS AND DISCUSSION}

The polymers were prepared by high temperature solution condensation method. It was observed that the polymer precipitated prematurely from the mixture solution when the feed ratio of trimer was beyond $50 \mathrm{~mol} \%$ because the increase of the rigid trimer content in the polymer chain easily led to the crystallization of product. Thus, it was difficult to obtain the higher molecular weight for the samples $60 / 40$, 80/ 20 and Homo-C. Both homopolymers and copolymers synthesized were not soluble in common organic solvents, because of which they suffered form a serious limitation in the determination of their molecular weights. Attempts were made to measure their solution viscosity in solvent mixtures to obtain an estimate of their molecular weight. It was evident that the majority of the polymers prepared had moderate molecular weights. But the three samples mentioned above were not soluble completely in mixing solvent even after heating.

The structure and properties of polymers were characterized by means of FT/IR, DSC, TGA and PLM. FT/IR results of TLCP (Figure 1(a)) showed the main characteristic absorptions at $1740 \mathrm{~cm}^{-1}$ and 1165 $\mathrm{cm}^{-1}$ attributed to ester group and $\mathrm{CF}_{3}$ group respectively. The characteristic absorptions peaks such as ester $\left(1740 \mathrm{~cm}^{-1}\right)$, ketone $\left(1647 \mathrm{~cm}^{-1}\right)$ and aromatic ether groups $\left(1243 \mathrm{~cm}^{-1}\right)$ for Homo-C was seen easily in Figure 1(c). A typical FT/IR spectrum for copolymer 40/60 presented in Figure 1(b) showed the characteristic absorption peaks containing both TLCP and Homo-C segments, which indicated the formation of link between ether ketone and polyester. 


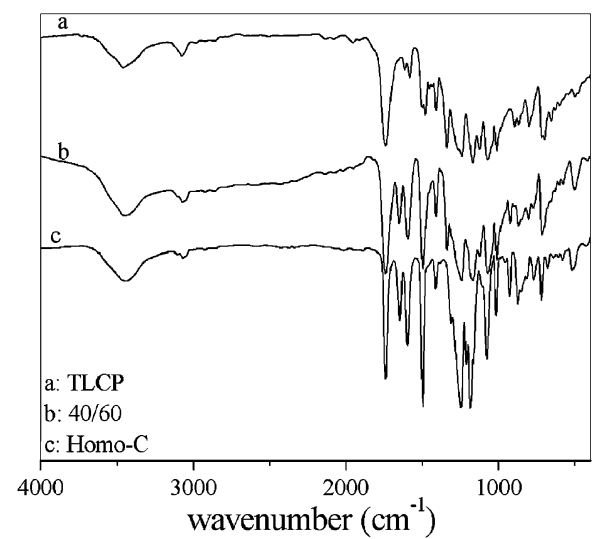

Figure 1. FT/IR spectra of three samples (a) TLCP, (b) 40/ 60, (c) Homo-C.

The data for the thermal properties of the polymers with different compositions were listed in Table I. From table melting endotherm was observed at $347.8^{\circ} \mathrm{C}$ for TLCP which was corresponding to a crystalline to nematic phase transition, but $T_{i}$ was not detected probably due to the detection limit in DSC because the thermotropic liquid crystalline behavior was confirmed by PLM. The DSC curves showed that the glass-transition temperature $\left(\mathrm{T}_{\mathrm{g}} \mathrm{s}\right)$ of the polymers ranged from $137.2^{\circ} \mathrm{C}$ to $168.8^{\circ} \mathrm{C}$. The variation of $\mathrm{T}_{\mathrm{g}}$ was observed to decrease at first and increase subsequently with the increment of the trimer content, i.e. surpassed a minimum. By introducing trimer into the TLCP main chain, the regularity was destroyed due to the copolymerization effect of trimer, thus $\mathrm{T}_{\mathrm{g}}$ and $\mathrm{T}_{\mathrm{m}}$ of the polymer were lowered accordingly. But when the rigid trimer continued to increase to some extent, the regularity increased and the transition temperatures increased again. Both the crystalline to liquid crystalline transition $\left(\mathrm{T}_{\mathrm{m}}\right)$ and liquid crystalline to isotropic transition $\left(\mathrm{T}_{\mathrm{i}}\right)$ were observed in the DSC curves of the copolymers 20/80, 40/60, 50/50 and $60 / 40$ which were further confirmed by PLM. The typical DSC curve for $20 / 80$ was shown in Figure 2. It was found that the range between $T_{m}$ and $T_{i}$ for the copolymer became narrow gradually

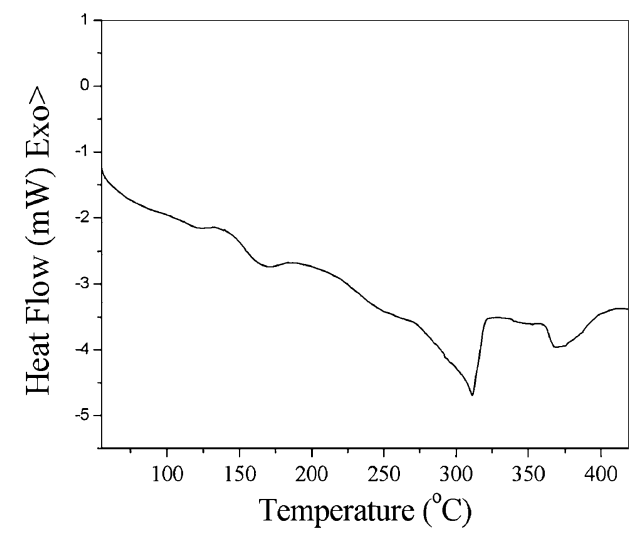

Figure 2. DSC thermogram of $20 / 80$.

with the addition of trimer. It was indicated that the excessive addition of trimer to the copolymers resulted in a gradual loss of liquid crystallinity and the mesophase stability, ${ }^{14}$ which was also verified by the reduction of enthalpies of transition for both $T_{m}$ and $\mathrm{T}_{\mathrm{i}}$. The trimer-based homopolymer had only a melting transition at $419.2^{\circ} \mathrm{C}$. It was also found that there existed two melting endotherms for $80 / 20$ at $384.8^{\circ} \mathrm{C}$ and $400.5^{\circ} \mathrm{C}$ respectively, the higher endotherm had a very low enthalpy compared to the lower one. It was suggested that there maybe existed a small part of higher regularity structure in the crystalline phase, resulting in the formation of a higher endotherm. There was a gradual increase in the melting ehthalpy $\left(\left(\mathrm{H}_{\mathrm{m}}\right)\right.$ with the increase of trimer content for 50/50, $60 / 40,80 / 20$, and Homo-C, with a suggestion of a great jump in crystallinity.

The thermal stability of all of the polymers was determined in air by TGA. The polymers showed a high stability, and the temperature at which $5 \%$ weight loss listed in Table I occurred varied from $402.6^{\circ} \mathrm{C}$ to $458.0^{\circ} \mathrm{C}$. The good thermal stability of the polymers was very useful for melt processing.

The WAXD diffractograms of samples were shown in Figure 3(A) and (B) and the corresponding data were listed in Table II. The WAXD diffraction of TLCP (Figure 3A(a)) showed a strong broad dis-

Table I. Properties of polymers

\begin{tabular}{ccccccrrr}
\hline Sample & Abbr. & $\begin{array}{c}\eta_{\mathrm{iv}} \\
(\mathrm{dL} / \mathrm{g})\end{array}$ & $\begin{array}{c}\mathrm{T}_{\mathrm{g}}{ }^{1} \\
\left({ }^{\circ} \mathrm{C}\right)\end{array}$ & $\begin{array}{c}\mathrm{T}_{\mathrm{m}} \\
\left({ }^{\circ} \mathrm{C}\right)\end{array}$ & $\begin{array}{c}\mathrm{T}_{\mathrm{i}} \\
\left({ }^{\circ} \mathrm{C}\right)\end{array}$ & $\begin{array}{c}\mathrm{H}_{\mathrm{m}} \\
(\mathrm{J} / \mathrm{g})\end{array}$ & $\begin{array}{c}\mathrm{H}_{\mathrm{i}} \\
(\mathrm{J} / \mathrm{g})\end{array}$ & $\begin{array}{c}\mathrm{T}_{\mathrm{d}}{ }^{2} \\
\left({ }^{\circ} \mathrm{C}\right)\end{array}$ \\
\hline 100TPC/100TFHQ & TLCP & 1.20 & 156.0 & 347.8 & - & 33.7 & - & 452.7 \\
100TPC/20Trimer/80TFHQ & $20 / 80$ & 0.58 & 149.1 & 310.7 & 374.4 & 15.5 & 5.1 & 441.9 \\
100TPC/40Trimer/60TFHQ & $40 / 60$ & 0.57 & 137.2 & 324.3 & 375.4 & 6.6 & 15.8 & 448.6 \\
100TPC/50Trimer/50TFHQ & $50 / 50$ & 0.88 & 140.3 & 325.9 & 352.6 & 4.3 & 3.4 & 458.0 \\
100TPC/60Trimer/40TFHQ & $60 / 40$ & - & 156.4 & 337.3 & 359.2 & 5.7 & 0.5 & 413.5 \\
100TPC/80Trimer/20TFHQ & $80 / 20$ & - & 165.3 & 384.8 & - & 38.9 & - & 402.6 \\
100TPC/100Trimer & Homo-C & - & 168.8 & 419.2 & - & 52.6 & - & 420.9 \\
\hline
\end{tabular}

1 determined from the $1^{\text {st }}$ cooling curve. 2 the temperature at $5 \%$ weight loss in the air. 

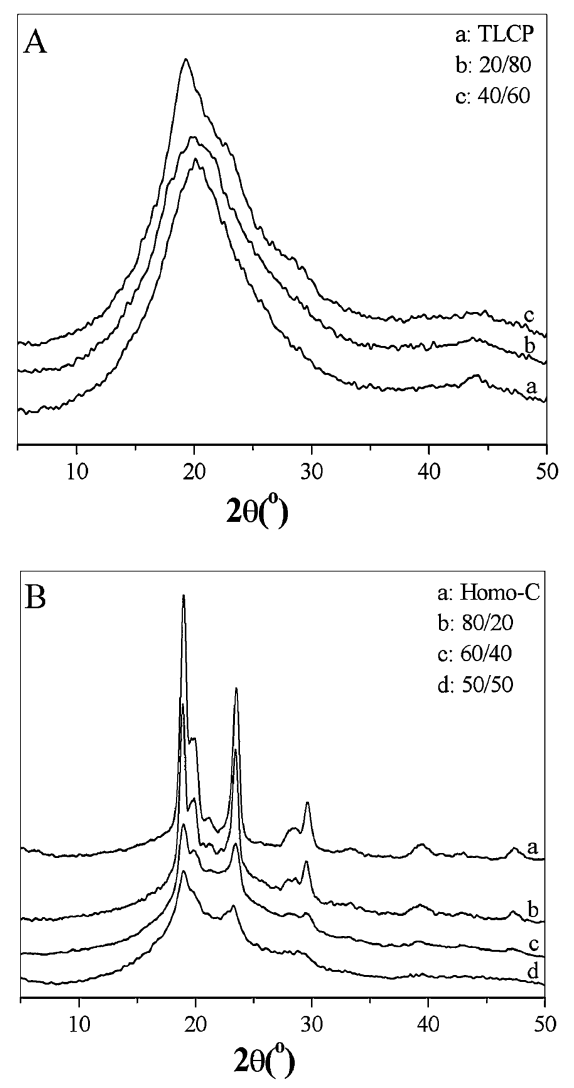

Figure 3. WAXD powder patterns of two groups of samples (A): (a) TLCP, (b) 20/80, (c) 40/60 and (B): (a) Homo-C, (b) $80 / 20$, (c) $60 / 40$, (d) $50 / 50$.

persed peak at $2 \theta=20^{\circ}$. There existed a lateral order in chain direction due to uniaxial orientation of the mesogenic macromolecules in domains, which was typical for nematic liquid crystalline copolyesters with random chain sequence distribution. ${ }^{15}$ Due to high content TFHQ as destroying the regularity of molecular chains in the copolymer, the samples 20/80 (Figure 3A(b)) and 40/60 (Figure 3A(c)) showed the similar diffraction patterns with TLCP's. Thus, these samples showed nematic liquid crystallinity. When the TFHQ content continued to decrease less than $60 \mathrm{~mol} \%$, there appeared the new diffraction peaks for the samples 80/20,60/40, 50/50 shown in Figure $3 \mathrm{~B}(\mathrm{~b})-(\mathrm{d})$ respectively. The WAXD diffractogram of Homo-C (Figure $3 \mathrm{~B}(\mathrm{a})$ ) showed sharp main crystalline reflections at $2 \theta=18.96^{\circ}, 19.84^{\circ}, 21.18^{\circ}$, $23.50^{\circ}, 28.58^{\circ}$ and $29.58^{\circ}$, representing a repeating unit in chain direction. WAXD diffractograms of samples showed a continuous change of the diffraction peaks from that crystallinity of Homo-C to liquid crystallinity of TLCP. From the diffractograms and table, the character of the diffraction profiles were observed to remain the same, there were no significant changes in the peak positions for the copolymers, i.e. d-spacings of each typical reflection were not changed correspondingly. The intensity of the diffrac-
Table II. Observed the main diffraction peak positions for samples

\begin{tabular}{ccccc}
\hline Samples & Homo-C & $80 / 20$ & $60 / 40$ & $50 / 50$ \\
\hline \multirow{6}{*}{$2 \theta\left(^{\circ}\right)$} & 18.96 & 18.90 & 18.94 & 18.96 \\
& 19.84 & 19.88 & 19.90 & - \\
& 21.18 & 21.22 & - & - \\
& 23.50 & 23.40 & 23.42 & 23.24 \\
& 28.58 & 28.58 & 28.70 & - \\
\hline
\end{tabular}

tion peaks decreased gradually and certain peaks disappeared at last with the increase of TFHQ content. Copolymers incorporated both crystallizable unit containing the ether-ketone-ester links and TLCP unit regularly spaced along the chain. When $\mathrm{x}=0.5,0.6$ and 0.8 , the unit containing ether-ketone-ester links predominated in the copolymer, thus, TLCP unit existed as defect in the crystallizable unit, resulting in a loss of liquid crystallinity. It was indicated that the crystalline structures of the copolymers were changed gradually in some extent and became more perfect accordingly, leading to an increase in crystallinty, consistent with the results mentioned above.

PLM was used to characterize the thermotropic liquid crystallinity of samples furthermore. The prepared thin films were heated to $420^{\circ} \mathrm{C}$ for $3-5 \mathrm{~min}$ in hot stage in order to remove the thermal history, then quickly cooled to the LC state, annealed at this temperature for some time to investigate the texture. A typical nematic liquid crystalline texture shown in Figure $4 \mathrm{a}$ was observed for the TLCP. A typical micrograph of 20/80 shown in Figure 4b exhibited a thread-like texture, which was often found in the nematic phase. It was found that the nematic textures formed for the 40/60 and 60/40 shown in Figure 4c and $\mathrm{d}$ respectively, which were a little different from the typical liquid crystalline texture. It was difficult to observe the melting of $80 / 20$ and $100 / 100$ by PLM, although the endotherm peaks were easily seen in their DSC curves. It needed further investigation.

\section{CONCLUSION}

Copolymers containing ether ketone and ester links were synthesized by high temperature solution condensation. The variation of $T_{g}$ and $T_{m}$ values in these polymers might have been caused by the copolymerization of third monomer and an increase in polymer chain rigidity, resulting in a reduction at first and an increase afterwards with the addition of trimer. The melting and isotropization transitions were both observed in the DSC curves for the copolymers containing 20, 40, 50 and $60 \mathrm{~mol} \%$ trimer. The typical textures of liquid crystalline were observed by PLM. It 


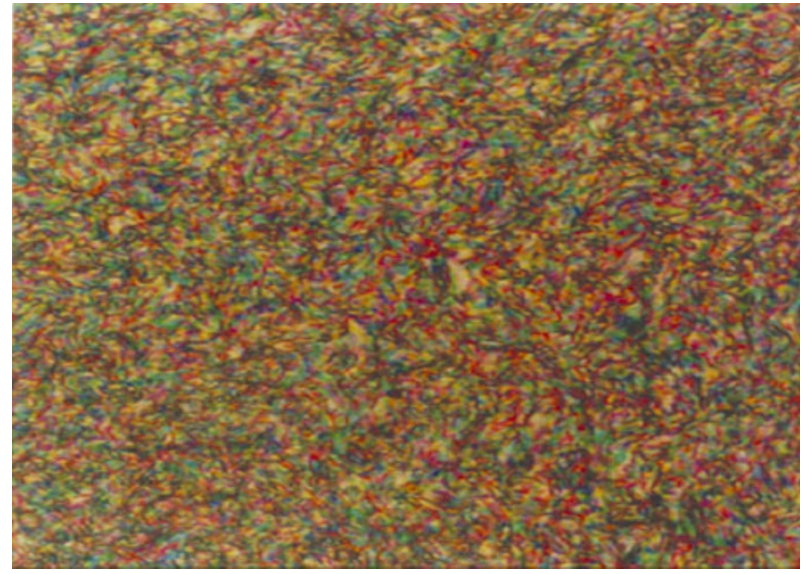

(a)

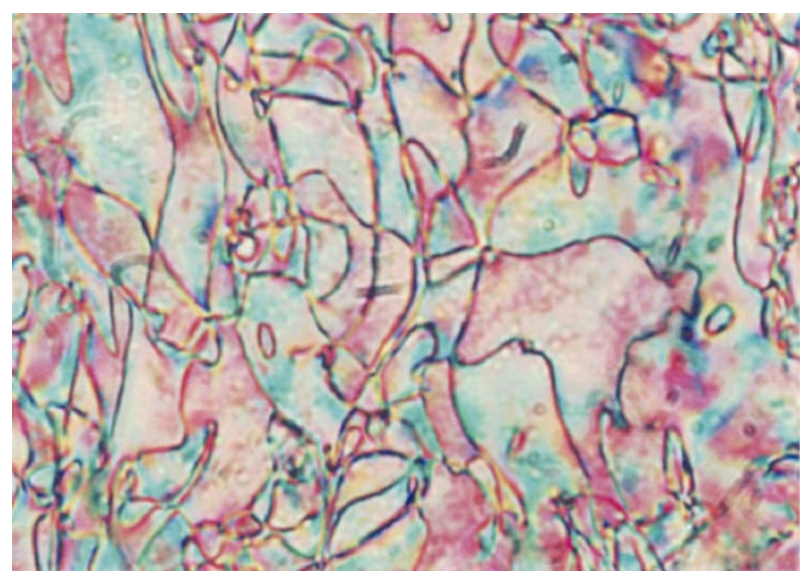

(b)

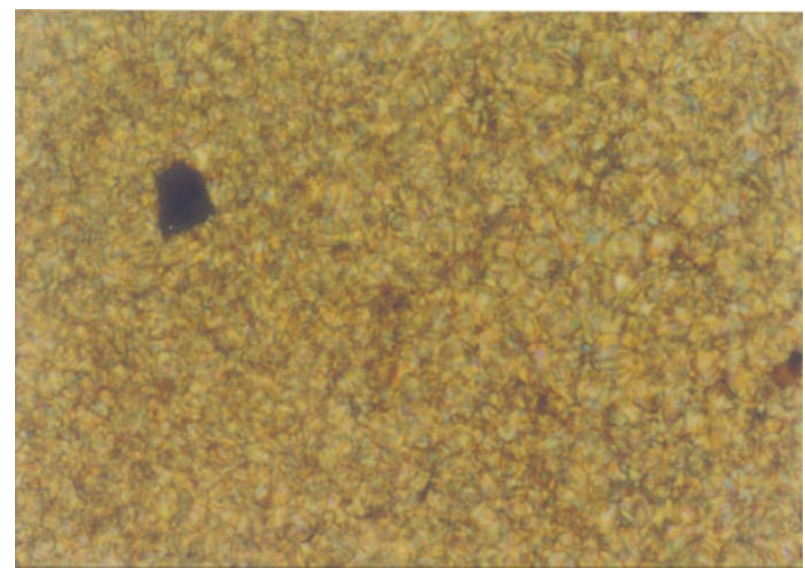

(c)

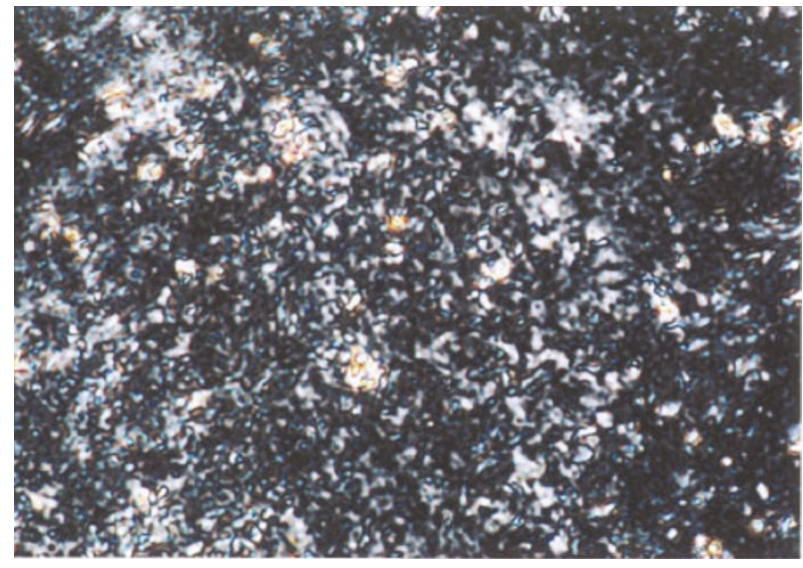

(d)

Figure 4. PLM of TLCP and copolymers (a) TLCP, (b) 20/80, (c) 40/60, (d) 60/40 above its $\mathrm{T}_{\mathrm{m}}$ (magnification 400×).

was found that the excessive addition of trimer resulted in a gradual loss of liquid crystallinity till only the melting endotherms appeared for copolymers containing 80 and $100 \mathrm{~mol} \%$ trimer. WAXD results indicated that the diffraction patterns for $20 / 80$ and $40 / 60$ copolymer showed similar ones with TLCP's, which suggested the complete liquid crystallinity. There appeared a new diffraction peaks for 50/50, 60/40, 80/ 20 and Homo-C attributed to an incease of rigid trimer content, which suggested the gradual loss of liquid crystallinity and enhancement of the crystallinity of the polymers.

\section{REFERENCES}

1. G. L. Tullos, P. E. Cassidy, and A. K. S. Clair, Macromolecules, 24, 6059 (1991).

2. J. B. Rose, Polymer, 15, 456 (1974).

3. J. B. Cattanach, G. Guff, and F. N. Gogswell, J. Polym. Eng., 6, 345 (1986).

4. W. J. Jackson, Mol. Liq. Cryst., 169, 23 (1989).
5. G. Kiss, Polym. Eng. Sci., 27, 410 (1987).

6. R. E. Bretas and D. G. Baird, Polymer, 33, 5233 (1992).

7. Y. Son, Y. Chun, and R. A. Weiss, Polym. Eng. Sci., 44, 541 (2004).

8. X. Zheng, J. Zhang, and J. He, J. Appl. Polym. Sci., 87, 1452 (2003).

9. M. Garcia, J. I. Eguiazábal, and J. Nazábal, Polym. Compos., 23, 592 (2002).

10. Y. H. Yang, W. C. Zhu, D. Jiang, R. T. Ma, and Z. H. Jiang, J. Appl. Polym. Sci., 104, 35 (2007).

11. Y. Ma, S. E. Wang, B. Q. Yang, H. F. Zhang, and Z. S. Mo, Chin. J. Appl. Chem., 13, 25 (1996).

12. G. B. Wang, C. H. Chen, H. W. Zhou, Z. H. Jiang, W. J. Zhang, and Z. W. Wu, Chem. Chinese Univer., 21, 1325 (2000).

13. Y. H. Yang, X. H. Dai, L. M. Zhang, R. T. Ma, and Z. H. Jiang, Polym. Adv. Technol., 18, 1466 (2007).

14. A. Coassolo, M. Foa, D. Dainelli, R. Scordamaglia, L. Barino, L. L. Chapoly, F. Rustichelli, B. Yang, and G. Torquati, Macromolecules, 24, 1701 (1991).

15. D. Pospiech, L. Häubler, H. Komber, D. Voigt, D. Jehnichen, A. Janke, A. Baier, K. Eckstein, and F. Böhme, J. Appl. Polym. Sci., 62, 1819 (1996). 